\title{
NUCLEAR GROWTH DURING EARLY DEVELOPMENT
}

IN reading Conklin's recent paper on the relative growth of nucleus and cytoplasm in developing eggs, ${ }^{1}$ I was at first somewhat puzzled by certain of the relations brought out. The matter is one that bears directly upon so many important problems, and Conklin's paper is one of such fundamental importance, that possibly a statement of the difficulty and its apparent solution may be worth while. Work done with the thoroughness that characterizes all that Conklin puts forth partakes to a certain degree of the inexhaustibleness of nature, in that it is possible to discover in it relations not explicitly set forth by the author.

Conklin's most notable result is that the relative proportions of nuclear and cytoplasmic materials do not appreciably change during early development, as they have been supposed to do. The bearing of this upon the theory that cleavage is a process of rejuvenescence, owing to the enormous increase of nuclear material relative to the cytoplasm, is evident. The point which I wish to discuss has no bearing upon this fundamental result, but relates to the rate of nuclear growth.

On this point Conklin sums up his results for Crepidula as follows :

"The rate and amount of nuclear growth during cleavage is much less than is generally believed. Whether the nuclear volume is taken when the nuclei are at their maximum, mean or minimum size, the nuclear growth is far from 100 per cent. or a doubling, in each division. In Crepidula the nuclear growth is not more than 5 per cent. to 9 per cent. for each division from the 2-cell to the 32-cell stage, and less than 1 per cent. for each division after the 32-cell stage" (p. 40).

Similar figures are given for the other animals studied.

Now, if I have gotten clear on the matter, what Conklin here means is that when any cell divides, the increase of nuclear material thus produced is on the average but 5 to 9 per cent. of the amount that was present in an early stage of the egg, and specifically in the two-cell stage. This is a different method of expressing the rate of growth from that often employed. The question perhaps most often answered when the rate of nuclear growth at cell division is given is the following: How much is

${ }^{1}$ Conklin, E. G., "Cell Size and Nuclear Size," Journal of Experimental Zoology, 12, 1-98. 
the nuclear material of a given cell increased when that cell divides? Or, what is essentially the same, when several cells are present, as usually in a developing egg: In what proportion is the total nuclear material increased when all of the cells divide once? It appears to me that these questions are the ones that have been in mind when it has been held that the nuclear material increases nearly 100 per cent. at each cleavage, so that the relation of the ratio used by Conklin to the ratio implied by them is of interest.

The ratio implied in the questions just set forth-the ratio of increase in the nuclear material of a given cell after that cell has divided-is of course obtained by dividing the nuclear volume of the two resulting cells by this volume in the mother cell; or by dividing the total nuclear volume of the egg after all its cells have divided once by the total volume before the cells divided. (Inclusion of several cells, each of which divides once, of course does not of itself alter the ratio.) Performing these operations for the mean nuclear volumes in Crepidula, as given in Conklin's Table 9, one finds the ratios in question to be for the second cleavage 1.40, for the third 1.25, for the fourth 1.19 , for the fifth 1.89. That is, in passing from the 2-cell to the 4-cell stage, the nuclear volume of each mother cell increases 40 per cent.; in passing from the 4-cell to the 8-cell stage, the increase is 25 per cent.; from the 8 - to the 16 -cell stage it is 19 per cent.; from the 16- to the 32-cell stage it is 89 per cent. These ratios are not 100 per cent. at each division, but they approach it more nearly than the ratio Conklin employs. If we average the increase for these four cleavages, we find the mean to be 43 per cent. That is, at each cleavage, the nuclear volume of the cell increases on the average by 43 per cent.

It may be noted that even with an absolutely constant ratio between the nuclear volume in a given cell before cleavage and that in its products after cleavage, the ratio employed by Conklin would, as a rule, if I have correctly interpreted it, decrease rapidly as we pass to later cleavage stages. The relation between the two ratios would be that shown by the following formula, in which $x=$ Conklin's ratio; $r=$ the (constant) ratio of the nuclear volume after division of a given cell to the nuclear volume before that division; $n=$ the number of the cleavage $(1,2,3$, etc.) :

$$
x=\frac{r^{n-1}-1}{2^{n}-2}
$$


For example, if $r=1.5$ (so that the nuclear volume of any cell increases 50 per cent. when that cell divides), then for the result of four cleavages (producing 16 cells) the formula gives

$$
x=\frac{(1.5)^{3}-1}{2^{4}-2}=\frac{2.375}{14}=16.96 \text { per cent. }
$$

If Conklin employed the 1-cell stage as his standard of comparison, the above formula would be

$$
x=\frac{r^{n}-1}{2^{n}-1} \text {. }
$$

It will be found that for any increase less than 100 per cent. of what was present before division (that is, $r=2$ ), Conklin's ratio (from formula 1 or 2 ) decreases in the later stages of cleavage, even though the law of increase, so far as each cell by itself is concerned, remains absolutely the same. Thus, if at the division of every cell its nuclear volume increases 50 per cent., Conklin's ratio (formula 1 ) will give 25 per cent. for the result of the second cleavage, 20.83 for the third, 16.96 for the fourth, 13.54 for the fifth, 10.64 for the sixth, 8.25 per cent. for the seventh, etc. This appears to be the reason why Conklin finds the rate of nuclear increase, as shown by his ratio, to be less in later stages; it is not due to any change in the relations so far as what happens in each cell is concerned.

H. S. JenNings

\section{IS THERE ASSOCIATION BETWEEN THE YELLOW AND AGOUTI FACTORS IN MICE?}

IN the generally accepted formulæ for the colors of mice, as worked out by Cuénot, Bateson, Durham and others, there is assumed to be a factor, $Y$, for self yellow color, ${ }^{1}$ which is epistatic to $T$, the ticking or agouti factor (also known as $G$ ). The various types have the following constitution:

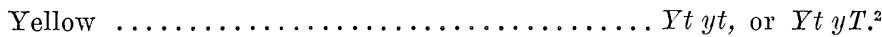

Agouti (including cinnamon) $\ldots \ldots \ldots \ldots \ldots y T y T$, or $y T y t$.

Black and chocolate (including dilute forms) ..yt yt. ${ }^{3}$

${ }^{1}$ On the formulæ adopted here this factor $Y$ is probably to be considered an inhibitor.

${ }^{2}$ It has been shown by Cuénot and others (see especially Castle and Little, Science, N. S., 32, 868, 1910) that mice homozygous for $\bar{Y}$ do not exist, the reason probably being that the $Y Y$ zygotes, though formed in the expected proportions, do not develop.

${ }^{3}$ Blacks differ from chocolates in having a black factor, $B$. Agoutis also carry this factor, while cinnamons lack it. Yellows may or may not bear it, but the two types are distinguishable by their eye color. 